DELTA UNIVERSITY
SCIENTIFIC JOURNAL
Journal home page: www.deltauniv.edu.eg/dusj

\title{
Proposed Framework for Predicting Stock Return Volatility Using Neural Network "An Applied Study on the Egyptian Stock Exchange Osama EL-Ansary ${ }^{1}$, Nazeer Elshahat ${ }^{2}$, Maha Metawea ${ }^{3}$ \\ ${ }^{1}$ Department of Business Administration, Faculty of Commerce ,Cairo University, Giza, Egypt. \\ ${ }^{2}$ Department of Business Administration, Faculty of Commerce,Mansoura University \\ ${ }^{3}$ Department of Business Administration, Faculty of Business Administration, Delta University \\ Abstract
}

Purpose: the main purpose of the study is to determine the effect of both internal and external factors on stock returns volatility using different statistical methods, applied on Egyptian stock exchange.

Methodology: the researchers have compared the accuracy of (GLS Model, GARCH Model, and Neural Network) in predicting the stock return volatility to choose the most accurate one. Data was collected from the Egyptian Stock Exchange (EGYX 30) for the period of (2014 to 2017) on monthly basis.

Findings: The results of the study revealed that the Neural Network Model has proven be outperform the traditional models in the prediction of stock return volatility.

Originality: the study contributes to literature as it used Artificial Neural Network in two functions (Prediction of stock return volatility) and (Classification of the volatility to -high volatility and Low volatility). Also few studies concerned with stock return volatility in developing countries, especially Egypt.

Key words: Stock Return Volatility, Artificial Neural Network, GARCH Model, GLS Model, Egyptian Stock Exchange.

\section{Introduction}

Increased globalization of financial market has made stock return volatility an important research topic and challenge for both: practitioners, researchers and policy makers. The most recent liberalization of economic policies and exchange rate regimes in many developing countries including Egypt have caused realignment of competitive structures of many emerging stock markets and their relative attractiveness to both local and global markets alike. This task will be achieved through the comparison between the degree of accuracy of the proposed Artificial Neural Network Model (ANN) against the accuracy of the alternative model - GARCH model which has dominated the research area for many years (Monfared and Enke, 2015). Moreover, the results of this study will provide a set of recommendations that are expected to be helpful to both individual and institutional investors in the Egyptian Stock Market in rationalizing their investment decisions on one hand and to the Egyptian policymakers in their efforts to improve market surveillance and efficiency on the other hand.

(Qiu and Song (2016) have indicated that it has always been a difficult task to predict the exact daily return of the stock market index; hence, there is a great deal of research being conducted regarding the prediction of the direction of stock return index movement. Many factors such as

Delta University for Science and Technology

Coastal International Road, Mansoura, Gamasa City, Dakahlia, Egypt

Journal homepage: www.deltauniv.edu.eg/dusj

E-mail: dusj@deltauniv.edu.eg

P a g e $\mid \mathbf{4 6}$ 
political events, general economic conditions, and traders, expectations may have an influence on the stock market index.

There are several definitions of stock return volatility. According to one of the leading definitions in this area, volatility is defined as a statistical measurement of the changes in returns or market index (Monfared and Enke, 2015) Volatility can be measured using either the standard deviation or variance between returns from the market index. Typically, a higher degree of volatility is considered more dangerous for stability in the field of finance. Other scholars in the area defines volatility is the degree of variation in a series of trading return over a certain period of time. (Chaudhuri and Indranil2016). Volatility is commonly measured by the standard deviation of returns where the symbol " $\sigma$ " is used as measure of volatility which should not be confused with the variance of the same name, which instead $\sigma 2$.

\section{2-literature review:}

According to literature review, numerous studies have attempted to explain effect of company specific factors on stock return volatility. Research conducted by Hartono (2005) examines the effect of a sequence of positive and negative dividend and earning information on stock returns.

Results show that the positive recent earning information has significant relation with stock returns when it follows negative dividend information, and the negative recent earning information has significant relation with stock returns when it follows positive dividend information.

Several studies thus far have linked Company specific factors with stock return volatility, Hashemijoo, et al (2012) study has showed significant negative relationship between share return volatility with two main measurements of dividend policy which are dividend yield and dividend payout. Moreover, a significant negative relationship between share return volatility and size is found.

A number of authors have reported a significant effect of macroeconomic variables on stock return volatility .Kasman, et al (2011) conducted a study on the effects of interest rate and foreign exchange rate changes on Turkish banks' stock market returns using the GARCH model. The sample consists of thirteen Turkish commercial bank stocks listed on the Istanbul Stock Exchange .They used daily closing individual Bank stock returns, the closing return of the bank index, exchange rates and interest rates. The period begins on 27 July 1999 and ends on 9 April 2009. The results have indicated that there's a negative and significant effect of interest rate and exchange rate changes on the conditional bank stock return. Also, Vikalp, et al (2018) conducted a detailed analysis of the different relations between the prediction and individual stock returns of financial sector companies in National Stock Exchange and a set of macroeconomic variables as independent variables. Result has shown that macroeconomic variables and physical factors will affect the share returns of the different stock returns. Because of the strong relation between the macroeconomic variables and different stock values it plays a vital role.

Erdem, et al (2005), also have studied the effect of macroeconomic variables on the Turkish stock exchange returns. The list of the independent variables used in the study included: exchange rate, interest rate, inflation, industrial

Delta University for Science and Technology

Coastal International Road, Mansoura, Gamasa City, Dakahlia, Egypt

Journal homepage: www.deltauniv.edu.eg/dusj

E-mail: dusj@deltauniv.edu.eg 
production and money supply. A GARCH model was used in the study to test the effect of macroeconomic variables on stock returns volatility. Results reveal unidirectional strong effect of inflation, interest rate on all stock return indexes. There are a strong effect of money supply on financial index, and from exchange rate to both IMKB 100 and industrial indexes. There is no effect of industrial production on any index.

On the other hand, many studies also have examined the use of ANN in the prediction of stock return volatility,

Chaudhuri and Ghosh (2016) conducted a comprehensive study on the use of Neural Network Models in the prediction of stock return volatility in the Indian stock market. In this study, the researchers used a back propagation algorithms type of neural network to make the prediction of the stock market volatility more accurate. The study model was based on the Indian VIX, CBOE VIX indices, and the volatility of crude oil returns (CRUDESDR), volatility of DJIA returns (DJIASDR), volatility of DAX returns (DAXSDR), volatility of Hang Seng Index returns (HANGSDR)and volatility of Nikkei returns (NIKKEISDR) as predictor variables. The study show that, only one hidden layer was used while number of hidden neurons has been varied at three levels (20, $30 \& 50$ respectively). Hence total number of trials was fifty four $(2 * 9 * 3)$. The time frame for this study has tested three different time periods. Framework of study could satisfactorily forecast volatility for 2015 using training data for 2013-15.

Agrawal, and Murarka (2015) study examined the Stock Return Trend Prediction using Artificial Neural Network and Derived Parameters. The researchers indicated that the use of neural networks in the field of finance has significantly increased over the last two decades. Furthermore, different types of Neural Network Models have been used in predicting stock returns and return fluctuations. The success of those models has the potential to bring numerous rewards - both academic and financial analysts. There are numerous reasons why neural networks offer an advantage in the quest to predict stock return fluctuations. There is only one widely accepted theory on stock returns and markets, called the Efficient Markets Hypothesis (EMH), which ultimately concludes that such return changes may never be predicted.

\section{3- Methodology:}

\section{3-1 The Sample:}

The largest, most actively trading companies representing the most popular Egyptian Stock Exchange indices - EGEX 30 - were included in the final sample of this study. The combined market value of these companies is more than $50 \%$ of the total Value of all listed companies.

\section{3-2 Data collection:}

1-The entire data set related to the internal variables used in the study were obtained from the Department of Economic Research of the Egyptian Stock Exchange. The Quarterly and Annual Financial reports for all listed companies - for the 2014-2017 periods - were extracted from the data set. Those companies include: the 30companies of the Egyptian Stock Exchange Index (EGEX 30) in addition to 10 other actively traded companies. After detailed examination of the data set, the Quarterly and Annual Financial reports for forty companies were selected for inclusion in the study sample. The final selection was made on the basis of data availability and consistency for whole study period.

Delta University for Science and Technology

Coastal International Road, Mansoura, Gamasa City, Dakahlia, Egypt

Journal homepage: www.deltauniv.edu.eg/dusj

E-mail: dusj@deltauniv.edu.eg 
2- The values of the Company Specific Variables (Log T.A, EPS, Price to Book Value and the average monthly Return used in the study were calculated.

3- Nine companies were excluded from the final sample due to the presence of some irregularities in the financial reports of those companies and the incompleteness of required data.

4- Data for the Macro Variables (Exchange rate, interest rate, Inflation Rate and GDP) were gathered from the monthly Economic Bulletins published by the Egyptian Central Bank over the study period.

5- Data were reviewed and compiled using Excel Sheets in which the study data set was arranged as: Columns Containing: Company name along with computed values of the study variables. Only two variables- Total assets and Gross National Product were transformed to the Log form due to their special nature - values made of several digits -in order to make them consistent with the values of other variables used in the study.

6 - As a normal practice in this type of studies, the data were preprocessed where extreme (outliers) were eliminated.

\section{3-3 framework for data analysis:}

As this study involves the use of three different Models: GLS (Generalized Least Squares) model, GARCH (Generalized Auto Regressive Conditional Heteroscedasticity model, and ANN ( Artificial Neural Network) model, the standard descriptive analysis is used to describe the main characteristics of data used - including mean, median, range, variance and standard deviations. In addition Correlation Matrices measuring the relationships among the study variables were also computed.

\section{3-4 Study Time -Frames:}

Two time frames were used in the study: Yearly Analysis and Full Period Analysis.Since the study period (20142017) has witnessed various types of economic and political changes including the implementation of the economic recovery program, the liberalization of the exchange rate regime and the unprecedented increase in interest rates in 2016, the First type of analysis (Yearly Analysis) was designed to gain more insights into the phenomenon under investigationStock Return Volatility on a year -byyear basis before conducting the Full Period Analysis.

\section{3-5 Statistical Analysis Techniques} and tests:

In this research, three techniques were used to determine the effect of (size of the company which represented in total assets, EPS and market to book value, Interest rate, Exchange rate, Inflation Rate and GDP) on stock return volatility:

1) GLS using SPSS Version 22

2) GARCH using E.views 10

3) Logit Regression Model using SPSS Version 22

4) ANN using Mat lab statistical program.

Statistical Analysis Tests:

1) Normality test: Fixed Vs Random

2) Different correlation coefficients (Spearman test)

3) Dickey- Fuller Test to test the stationary or non-stationary of data.

4) Root Square Error.

5) Mean Square Error

3-6 study hypotheses:

1-There's a statistical significant relationship between the selected set of independent variables both internal (size of the company represented by total assets, EPS and market to book value) and external (Interest rate. Exchange rate, Inflation Rate, GDP and stock return volatility using GLS Regression

Delta University for Science and Technology

Coastal International Road, Mansoura, Gamasa City, Dakahlia, Egypt

Journal homepage: www.deltauniv.edu.eg/dusj

E-mail: dusj@deltauniv.edu.eg 
2-There's a statistical significant relationship between the selected set of independent variables both internal (size of the company represented by total assets, EPS and market to book value) and external (Interest rate. Exchange rate, Inflation Rate, GDP and stock return volatility using GARCH Model.

3- There's a statistical significant relationship between the selected set of independent variables both internal (size of the company represented by total assets, EPS and market to book value) and external (Interest rate. Exchange rate, Inflation Rate, GDP and stock return volatility using ANN Model.

4- ANN can achieve better predictive accuracy than LOGIT Method in the classification of the stocks traded in the Egyptian Exchange into "High Volatility and Low Volatility.

5- There is no significant difference between the predictive accuracy of The Neural Network Model and the competing statistical models GLS and GARCH models.

\section{4- Empirical results and testing hypothesis:}

1- First hypothesis: There's a statistical significant relationship between the selected set of independent variables both internal (size of the company - represented by total assets, EPS and market to book value) and external (Interest rate. Exchange rate, Inflation Rate, GDP and stock return volatility using GLS Regression

Delta University for Science and Technology

Coastal International Road, Mansoura, Gamasa City, Dakahlia, Egypt

Journal homepage: www.deltauniv.edu.eg/dusj

E-mail: dusj@deltauniv.edu.eg 


\begin{tabular}{|c|c|c|c|c|c|c|c|c|c|c|c|}
\hline & & & $\begin{array}{l}\text { log- } \\
\text { TA } \\
\end{array}$ & EPS & P-BV & Mean & $\begin{array}{l}\text { Int- } \\
\text { rate }\end{array}$ & $\begin{array}{c}\text { Exche } \\
\text { Rate }\end{array}$ & Inf rate & $\begin{array}{l}\text { log- } \\
\text { GDP }\end{array}$ & STD \\
\hline \multirow{27}{*}{ 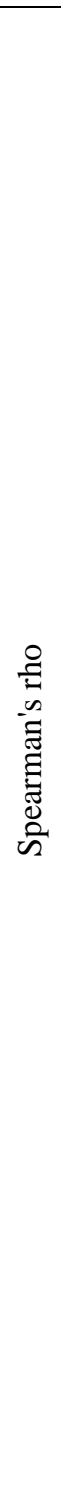 } & \multirow{3}{*}{$\log -\mathbf{T A}$} & $\begin{array}{c}\text { Correlation } \\
\text { Coefficient }\end{array}$ & 1.000 & & & & & & & & \\
\hline & & Sig. (2-tailed) & . & & & & & & & & \\
\hline & & $\mathbf{N}$ & 1390 & & & & & & & & \\
\hline & \multirow{3}{*}{ EPS } & $\begin{array}{l}\text { Correlation } \\
\text { Coefficient }\end{array}$ & $.247^{* *}$ & 1.000 & & & & & & & \\
\hline & & Sig. (2-tailed) & .000 & . & & & & & & & \\
\hline & & $\mathbf{N}$ & 1390 & 1390 & & & & & & & \\
\hline & \multirow{3}{*}{ P-BV } & $\begin{array}{c}\text { Correlation } \\
\text { Coefficient }\end{array}$ & $-.105^{* *}$ & .045 & 1.000 & & & & & & \\
\hline & & Sig. (2-tailed) & .000 & .092 & & & & & & & \\
\hline & & $\mathbf{N}$ & 1390 & 1390 & 1390 & & & & & & \\
\hline & \multirow{3}{*}{ Mean } & $\begin{array}{c}\text { Correlation } \\
\text { Coefficient }\end{array}$ & .034 & .049 & $.104^{* *}$ & 1.000 & & & & & \\
\hline & & Sig. (2-tailed) & .209 & .067 & .000 & $\cdot$ & & & & & \\
\hline & & $\mathbf{N}$ & 1390 & 1390 & 1390 & 1390 & & & & & \\
\hline & \multirow{3}{*}{ Int-rate } & $\begin{array}{c}\text { Correlation } \\
\text { Coefficient }\end{array}$ & -.002 & -.042 & $-.173^{* *}$ & -.012 & 1.000 & & & & \\
\hline & & Sig. (2-tailed) & .953 & .121 & .000 & .660 & & & & & \\
\hline & & $\mathbf{N}$ & 1390 & 1390 & 1390 & 1390 & 1390 & & & & \\
\hline & \multirow{3}{*}{$\begin{array}{c}\text { Exchange } \\
\text { Rate }\end{array}$} & $\begin{array}{c}\text { Correlation } \\
\text { Coefficient }\end{array}$ & -.037 & $-.088^{* *}$ & $-.117^{* *}$ & -.044 & $.738^{* *}$ & 1.000 & & & \\
\hline & & Sig. (2-tailed) & .167 & .001 & .000 & .098 & .000 & & & & \\
\hline & & $\mathbf{N}$ & 1390 & 1390 & 1390 & 1390 & 1390 & 1390 & & & \\
\hline & \multirow{3}{*}{$\begin{array}{l}\text { Inflation } \\
\text { rate }\end{array}$} & $\begin{array}{c}\text { Correlation } \\
\text { Coefficient }\end{array}$ & -.003 & $-.070^{* * *}$ & $-.066^{*}$ & $-.101^{* *}$ & $.238^{* *}$ & $.363^{* *}$ & 1.000 & & \\
\hline & & Sig. (2-tailed) & .899 & .009 & .013 & .000 & .000 & .000 & . & & \\
\hline & & $\mathbf{N}$ & 1390 & 1390 & 1390 & 1390 & 1390 & 1390 & 1390 & & \\
\hline & \multirow{3}{*}{ log-GDP } & $\begin{array}{c}\text { Correlation } \\
\text { Coefficient }\end{array}$ & -.011 & .034 & -.021 & -.009 & -.011 & -.008 & .003 & 1.000 & \\
\hline & & Sig. (2-tailed) & .681 & .205 & .428 & .750 & .669 & .765 & .911 & . & \\
\hline & & $\mathbf{N}$ & 1390 & 1390 & 1390 & 1390 & 1390 & 1390 & 1390 & 1390 & \\
\hline & \multirow{3}{*}{ STD } & $\begin{array}{c}\text { Correlation } \\
\text { Coefficient }\end{array}$ & $-.195^{* *}$ & $-.067^{*}$ & $.057^{*}$ & $.084^{* *}$ & $.086^{* *}$ & $.118^{* *}$ & $.171^{* *}$ & .041 & 1.000 \\
\hline & & Sig. (2-tailed) & .000 & .012 & .034 & .002 & .001 & .000 & .000 & .127 & \\
\hline & & $\mathbf{N}$ & 1390 & 1390 & 1390 & 1390 & 1390 & 1390 & 1390 & 1390 & 1390 \\
\hline \multicolumn{12}{|c|}{ **. Correlation is significant at the 0.01 level (2-tailed). } \\
\hline & & & & & & & 1 & it & & & \\
\hline
\end{tabular}

Results have shown that the relationship between :P-BV, Mean Stock Return ,Int. -Rate, Exchange Rate, Inflation Rate and Standard Deviation is significant with a positive sign as the corresponding P-values are less than 0.05 and correlation coefficients are $0.057,0.084,0.086,0.118$ and 0.171 respectively. The reported results also show that there is a significant negative relation between Log-TA, EPS and Standard Deviation with corresponding P-values less than 0.05 and correlation coefficients of -0.195 and 0.067. Log of GDP is insignificant.

2- Second hypothesis: There's a statistical significant relationship between the selected set of independent

Delta University for Science and Technology

Coastal International Road, Mansoura, Gamasa City, Dakahlia, Egypt

Journal homepage: www.deltauniv.edu.eg/dusj

E-mail: dusj@deltauniv.edu.eg 
variables both internal (size of the company - represented by total assets, EPS and market to book value) and external
(Interest rate. Exchange rate, Inflation Rate, GDP and stock return volatility using GARCH Model

\begin{tabular}{|c|c|c|c|c|}
\hline \multicolumn{3}{|c|}{ Dependent Variable: STD } & & \\
\hline \multicolumn{5}{|c|}{ Method: ML - GARCH (Marquardt) - Normal distribution } \\
\hline \multicolumn{2}{|l|}{ Sample: 11390} & & & \\
\hline \multicolumn{3}{|c|}{ Included observations: 1390} & & \\
\hline \multicolumn{4}{|c|}{ Convergence achieved after 468 iterations } & \\
\hline \multicolumn{5}{|c|}{ Presample variance: backcast (parameter $=0.7$ ) } \\
\hline \multicolumn{5}{|c|}{$\mathrm{GARCH}=\mathrm{C}(11)+\mathrm{C}(12)^{*} \mathrm{RESID}(-1)^{\wedge} 2+\mathrm{C}(13)^{*} \mathrm{GARCH}(-1)$} \\
\hline Variable & Coefficient & Std. Error & Z-Statistic & Prob. \\
\hline EPS & 0.000140 & 0.000197 & 0.714601 & 0.4749 \\
\hline EXCHANGE_RATE & $1.09 \mathrm{E}-05$ & 0.000123 & 0.088767 & 0.9293 \\
\hline INFLATION_RATE & 0.001170 & 0.000251 & 4.655937 & 0.0000 \\
\hline INT_RATE & 0.112219 & 0.034410 & 3.261235 & 0.0011 \\
\hline LOG_GDP & 0.008515 & 0.002851 & 2.986832 & 0.0028 \\
\hline LOG_TA & -0.001251 & 0.000306 & -4.082456 & 0.0000 \\
\hline MEAN & 0.024512 & 0.032034 & 0.765168 & 0.4442 \\
\hline P_BV & 0.002680 & 0.000198 & 13.52461 & 0.0000 \\
\hline PRICE & 0.000126 & $4.63 \mathrm{E}-05$ & 2.722805 & 0.0065 \\
\hline \multirow[t]{2}{*}{$\mathrm{C}$} & -0.005691 & 0.008553 & -0.665456 & 0.5058 \\
\hline & \multicolumn{2}{|c|}{ Variance Equation } & & \\
\hline $\mathrm{C}$ & $5.22 \mathrm{E}-05$ & $2.81 \mathrm{E}-06$ & 18.56515 & 0.0000 \\
\hline $\operatorname{RESID}(-1)^{\wedge} 2$ & 0.645145 & 0.077737 & 8.299047 & 0.0000 \\
\hline GARCH(-1) & 0.110321 & 0.030889 & 3.571484 & 0.0004 \\
\hline R-squared & -1.336088 & \multicolumn{2}{|c|}{ Mean dependent var } & 0.022558 \\
\hline Adjusted R-squared & -1.351323 & \multicolumn{2}{|c|}{ S.D. dependent var } & 0.010633 \\
\hline S.E. of regression & 0.016304 & \multicolumn{2}{|c|}{ Akaike info criterion } & -6.321236 \\
\hline Sum squared resid & 0.366840 & \multicolumn{2}{|c|}{ Schwarz criterion } & -6.272256 \\
\hline Log likelihood & 4406.259 & \multicolumn{2}{|c|}{ Hannan-Quinn criter. } & -6.302920 \\
\hline Durbin-Watson stat & 0.975247 & & & \\
\hline
\end{tabular}

Results have shown that the relationship between :P-BV, Int. -Rate, Inflation Rate and Log GDP and Standard Deviation is significant with a positive sign as the corresponding P-values are less than 0.05 and correlation coefficients are $0.00,0.0011$, $0.000,0.0028$ respectively. The reported results also show that there is a significant negative relation between Log-TA and Standard Deviation with corresponding P-values less than 0.05 and correlation coefficients of -0.0125.Mean, EPS, and Exchange rate insignificant.

3- Third hypothesis: There's a statistical significant relationship between the selected set of independent variables both internal (size of the company - represented by total assets, EPS and market to book value) and external (Interest rate. Exchange rate, Inflation Rate, GDP and stock

Delta University for Science and Technology

Coastal International Road, Mansoura, Gamasa City, Dakahlia, Egypt

Journal homepage: www.deltauniv.edu.eg/dusj

E-mail: dusj@deltauniv.edu.eg 
return volatility using ANN
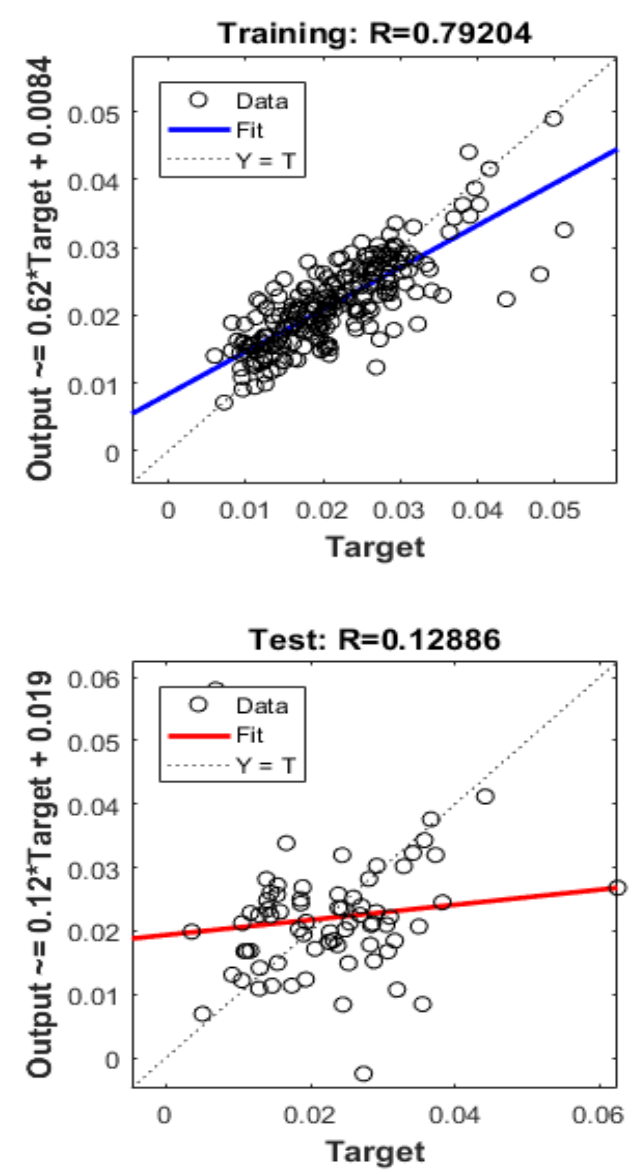

The fitted line produced by the neural network model - as shown on Figure 518 - measures the joint effects of the independent variables (Input Variables) on the dependent variable (the output variable) and as such it resembles the coefficient of determination produced by the standard statistical models. The overall performance is equal to $49,11 \%$ which will be evaluated against the other traditional models (GLS and GARCH).

4- Hypothesis four: ANN can achieve better predictive accuracy than LOGIT Method in the classification

Matrix for Neural Network

\begin{tabular}{|c|c|c|c|}
\hline $\begin{array}{c}\text { Predicted } \\
\text { Actual }\end{array}$ & High & Low & Total \\
\hline High & $314(51 \%)$ & $303(49 \%)$ & $617(100 \%)$ \\
\hline Low & $113(13 \%)$ & $750(87 \%)$ & $863(100 \%)$ \\
\hline Total & 427 & 1053 & 1480 \\
\hline
\end{tabular}

Model
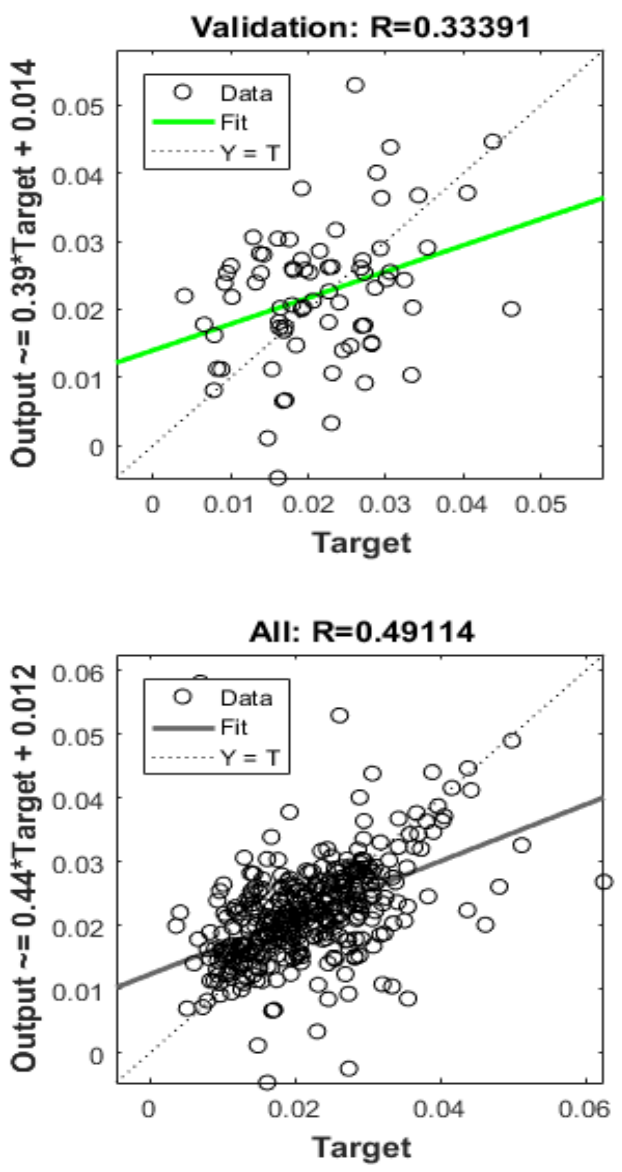

of the level of volatility (high) and (Low) for the Egyptian stocks.

The percentage of correct classification for the neural network model is $72 \%$ while the percentage of correct classification for the Logit model is $70 \%$ which illustrated in the two following matrix:

\begin{tabular}{|c|c|c|c|}
\multicolumn{4}{|c|}{ Matrix Sor Logit Model } \\
\hline $\begin{array}{c}\text { Predicted } \\
\text { Actual }\end{array}$ & High & Low & Total \\
\hline High & $346(56 \%)$ & $271(44 \%)$ & $617(100 \%)$ \\
\hline Low & $146(19 \%)$ & $699(81 \%)$ & $863(100 \%)$ \\
\hline Total & 510 & 970 & 1480 \\
\hline \hline
\end{tabular}

Delta University for Science and Technology

Coastal International Road, Mansoura, Gamasa City, Dakahlia, Egypt

Journal homepage: www.deltauniv.edu.eg/dusj

E-mail: dusj@deltauniv.edu.eg 
5- Hypothesis five: There is no significant difference between the predictive accuracy of The Neural Network Model and the competing statistical models GLS and GARCH models.

\section{5-Conclusion:}

Regarding the Size Factor as represented by the Log of total assets, several previous studies have examined the effect of company size on the stock return volatility. Cheung and Lillian 1992 have studied stock price dynamics and firm size, and results indicated that there was a negative relation between company size and stock return volatility. In other words, the stocks of large companies tend to have much lower volatility than their smaller counterparts. Investors tend to retain stocks of large companies for longer period as compared to their holdings of shares of smaller companies. This tendency contributes to the decrease the volatility of stock returns of large companies. The findings of the current study confirm the existence of significant negative impact for the company size on the stock return volatility.

On the other hand, Bayo. et, al (2016) study revealed that the company size total assets- has no significant impact stock return volatility.

Regarding the Earning -Per-Share (EPS) variable, several studies have indicated that there is a significant positive effect for EPS on stock return volatility. Those studies include: Hartono (2005), Velankar, et al (2017), which reveal the existence a significant positive relation between EPS and stock price volatility. Those findings are in line with the findings of the current study.

As for Price to Book Value variable (P/BV), few studies have examined its
Comparative analysis over the three used models

\begin{tabular}{|c|c|}
\hline Model Name & Value of MSE \\
\hline GLS & 0,011 \\
\hline GARCH & 0,008 \\
\hline ANN & 0,002 \\
\hline
\end{tabular}

effect on stock return volatility. Among those studies the study of Osundina, et al., (2016) which has investigated the impact of accounting information including $\mathrm{P} / \mathrm{BV}$-on stock price volatility. The reported results are in line with findings of the current study as both studies confirm the existence of a significant positive relation between Price-to-Book Value and stock return volatility.

With regard to the Mean Stock Return (Mean) some previous studies examined its impact on stock return volatility. A leading study by Haugen, R (1991) has examined the effect of the level of stock return on the on the level of volatility of share prices. The reported results showed a negative relationship between the level of stock return and the level of volatility of share prices. This finding is incompatible with the findings of the current study which indicated the Mean Stock Return has a significant positive impact on the volatility of stock returns. As for Inflation Rate variable, several previous studies have examined its impact on stock return volatility. Those studies include: Erdem, et al (2005). The results of those studies show that there is a strong negative effect of inflation rate on stock return volatility. The results of the current study confirm the findings of previous studies in the area. Those studies concluded that it is helpful to investors to have better understanding of the impact of inflation on market risk - as measured by return volatility when selecting the appropriate investment strategy. 
Regarding the Exchange Rate and Interest rate variables, a number of previous studies have investigated their relative impact on the stock return volatility. Those studies include: Kasman, et al (2011), khaled (2017), Nesrin, Et, al (2018). Those studies have reported a significant negative impact on the stock return volatility. These results are in line with findings of the current study.

For the GDP variable: many studies have studied the effect of GDP on stock return volatility and reveal a positive relation, but in our study, with given data, there's insignificant effect of GDP on stock return volatility.

\section{6- Recommendation and further research: \\ 6-1 recommendation:}

1 - Policy makers can use the findings of this study in the formulation of regulatory frameworks and market surveillance procedures designed to improve the functioning of the Egyptian stock market.

2 - Policy makers should take into consideration the potential impacts of economic actions of the foreign countries on the level of volatility in the Egyptian stock markets and design appropriate policies to protect Egyptian stock market from the potential impact of those actions.

3 -Investors may use the findings of this study in their portfolio selection decisions since the two main criteria considered in the portfolio selection are: risk (measured by volatility) and return.

4 -Managers of investment Funds and other Institutional Investors can use the findings of this study in the selection of appropriate securities to be included in their funds. Since most funds have risk tolerance objectives which are strong related to the level of stock return volatility.

\section{6-2 further work:}

1- Further studies could advance our knowledge about other regions like a MENA region and other emerging markets such as Turkey, South Africa and India.

2- Comparative study should be conducted between developing and developed countries which will allow researchers to identify factors affect stock return volatility in developed versus developing countries.

3- Further studies show include the investigation of stock return volatility in periods of boom and recession in order to investigate the impact of business cycle on the stock return volatility in various economic conditions.

4- Future studies on stock return volatility should be expanded to study the impact of Economic Reform programs on stock return volatility by comparing the level of volatility before and after the implementation of those reforms.

5- Further studies should include the impact of the level of foreign investors holding of Egyptian shares and their actions (massive sales and massive purchases) on stock return volatility.

6- Future researches should be expanded to include the potential impact of tax reforms including the capital 
gain tax on stock trading on the level of stock return volatility in the Egyptian stock market

\section{References:}

1- Almasi Monfared, Soheil \& Enke, David. (2014). Volatility forecasting using a hybrid GJR-GARCH neural network model. Procedia Computer Science. 36. 10.1016/j.procs.2014.09.087.

2- Qiu M, Song Y (2016)." Predicting the Direction of Stock Market Index Movement Using an Optimized Artificial Neural Network Model" . PLoS ONE Vol 11No. 5: e0155133.

3- Chaudhuri, T. D., \& Ghosh, I. (2016). Artificial neural network and time series modeling based approach to forecasting the exchange rate in a multivariate framework.

4- Hartono, J. (2004). The recently effect of accounting information. Gadjah Mada International Journal of Business, 6(1), 85-116.

5- Hashemijoo, Mohammad and Mahdavi-Ardekani, Aref and Younesi, Nejat, (2012). "The Impact of Dividend Policy on Share Return Volatility in the Malaysian Stock Market" Journal of Business Studies Quarterly, Vol. 5, No. 1,

6- Kasman , Saadet, Vardar, Gülin, and Tunç Gökçe (2011). "The Impact of Interest Rate And Exchange Rate Volatility On Banks' Stock Returns And Volatility: Evidence From Turkey". Economic Modeling Vol.28 issue 3 p.p: 1328-1335.
7- Vikalp Ravi Jain, Manisha Gupta, Raj Mohan Singh, (2018). " Analysis and Prediction of Individual Stock Prices of Financial Sector Companies in NIFTY50", International Journal of Information Engineering and Electronic Business(IJIEEB), Vol.10, No.2, pp. 33-41.

8- Erdem, Cumhur \& Kaan Arslan, Cem \& Sema Erdem, Meziyet. (2005). Effects of macroeconomic variables on Istanbul stock exchange indexes. Applied Financial Economics. 15. 987-994.

9- Agrawal, S., \& Murarka, P. (2015). "Stock Return Trend Prediction using Artificial Neural Network and Derived Parameters" International Journal of Advanced Research in Computer Science and Software Engineering,Vol.5 issue 2 p.p 1-6.

10- Cheung, Y., \& Ng, L. (1992). Stock Price Dynamics and Firm Size: An Empirical Investigation. The Journal of Finance, 47(5), 1985-1997.

11- Olaoye, Bayo \& Olayinka, Ifayemi \& Ajibade, Ayodeji \& Oluwatosin Akinyemi, T. (2016). Profitability and Stock Price Volatility of Nigerian Listed Manufacturing Companies. 7.

12- Osundina, J \& , Ademola \& Jayeoba, Olajumoke \& Olayinka, Ifayemi. (2016). Impact of Accounting Information on Stock Price Volatility (A Study of Selected Quoted Manufacturing Companies in Nigeria). The International Journal of Business and Management Research. 5. 
13- Haugen, R., Talmor, E., \& Torous, W. (1991). The Effect of Volatility Changes on the Level of Stock Prices and Subsequent Expected Returns. The Journal of Finance, 46(3)

14- Khalid, Waqar. (2017). Effects of Interest Rate and Exchange Rate on The Stock Market Performance Of Pakistan: A Co Integration Approach. Journal of Finance and Economics. 5.

15- Nesrine Mechri, Ben Hamad, Christian Perettiand, and Sahar Charfi. The Impact of the Exchange Rate Volatilities on Stock Market Returns Dynamic. 2018. 